\title{
LINGUÍSTICA TEXTUAL E SOCIOCOGNIÇÃO: INTERAÇÃO E CONHECIMENTOS VOLTADOS PARA A CONSTRUÇÃO DOS SENTIDOS
}

\author{
TEXTUAL LINGUISTICS AND SOCIAL COGNITION: INTERACTION AND \\ KNOWLEDGE FOR THE CONSTRUCTION OF MEANING
}

\author{
Valdinar Custódio Filho ${ }^{1}$, Débora Liberato Arruda Hissa ${ }^{2}$
}

\begin{abstract}
RESUMO: Este artigo, de feição eminentemente teórica, propõe uma discussão sobre as relações entre o sociocognitivismo e a linguística textual, com o objetivo de demonstrar que essas duas propostas investigativas convergem de tal modo que os princípios sociocognitivistas que embasam o fenômeno da cognição em interação são fundamentais para o tratamento teórico das estratégias de construção dos sentidos por meio dos textos (reveladas, principalmente, por meio da construção da referência). Isso resulta num entendimento das relações entre linguagem, percepção e realidade como pautadas pelo dinamismo comunicativo. Esclarecem esse dinamismo as ideias difundidas por Maturana (1998), Koch e Cunha-Lima (2005), Salomão (1999) e Blikstein (2003). Pretendemos, com essa discussão, reafirmar a posição de que a linguística textual - perspectiva teórica essencialmente interdisciplinar-enriquece seu fazer teórico ao explicitar os diálogos que trava com as propostas epistemológicas que lidam com o redimensionamento dos conceitos de conhecimento, cultura e realidade.
\end{abstract}

PALAVRAS-CHAVE: linguística textual; sociocognição; interação; construção dos sentidos.

ABSTRACT: This theoretical article proposes a discussion about the relation between sociocognitivism and textual linguistics, in order to demonstrate that these two investigative proposals converge in such a way that sociocognitivist principles (which underpin the phenomenon of cognition in interaction) are fundamental for the theoretical treatment of the strategies of construction of meaning through texts (mainly revealed through the construction of the reference). This results in an comprehension of the relation between language, perception and reality as guided by communicative dynamism. The ideas spread by Maturana (1998), Koch and Cunha-Lima (2005), Salomão (1999) and Blikstein (2003) clarify this dynamism. With this discussion, we intend to reaffirm the position that textual linguistics - a theoretical perspective that is essentially interdisciplinary - enriches its theoretical role by explaining the dialogues taken with epistemological proposals that deal with the reshaping of concepts such as knowledge, culture and reality.

\footnotetext{
1 Doutor em linguística pela Universidade Federal do Ceará (UFC). Professor Adjunto I da Universidade Estadual do Ceará (UECE).

${ }^{2}$ Doutora em Linguística Aplicada pela Universidade Estadual do Ceará (UECE)
} 
KEYWORDS: textual linguistics; social cognition; interaction; construction of meaning.

\section{Introdução}

Já é bastante sabido que a linguística textual (LT), em sua feição atual, revela uma forte tendência sociocognitiva (KOCH, 2003, 2004). Contudo, não é sempre que a relação entre a LT e o sociocognitivismo é suficientemente destrinchada. Considerando a motivação para a publicação desta edição da revista Organon - apresentar trabalhos que invistam nos elementos constitutivos do arcabouço teórico da LT -, intentamos, com esse artigo, trazer algum detalhamento sobre os pressupostos sociocognitivos da disciplina.

Para tanto, partimos de uma definição do que vem a ser o paradigma sociocognitivo (tomando como base as ideias de Maturana e colaboradores e de Koch e Cunha-Lima), desenvolvendo esse conceito na exposição de duas condições: a importância da interação e a instabilidade do real. Em seguida, propomos uma discussão sobre a relação entre linguagem e cognição, para o que é necessário mostrar, de um lado, como os estudos sobre linguagem são utilizados pelas teorias da cognição e, de outro lado, como os estudos sobre (socio)cognição são utilizados pelas teorias da linguagem (particularmente, a LT). Neste momento, destacamos o que falam Salomão (1999) e Blikstein (2003).

Pretendemos, com essa abordagem, contribuir para o entendimento dos parâmetros epistemológicos que embasam a Linguística Textual da atualidade, reforçando o caráter interdisciplinar que essa área do conhecimento não só assume, mas estimula. Julgamos que esta abordagem pode ser útil para que os interessados em se aprofundar no entendimento sobre a LT se inteirem dos princípios basilares da disciplina e, posteriormente, consigam perceber a consistência desses princípios em análises empíricas.

\section{A cognição em interação}

As ciências cognitivas têm como objeto de estudo o conhecimento e conteúdos correlatos, tais como aprendizagem, inteligência, memória e pensamento. Grosso modo, 
pode-se dizer que a preocupação maior das pesquisas reside na natureza do conhecimento - o que é e quais são seus tipos - e no "caminho" do conhecimento como ele é adquirido, como é armazenado, como é ativado quando necessário.

A sociocognição se coloca como uma proposta que compreende o tratamento do conhecimento de forma peculiar em relação aos estudos cognitivos clássicos, em que a cognição é entendida como uma dimensão "isolada" do corpo (KOCH e CUNHALIMA, 2005). Neste novo paradigma, parte-se do princípio de que os sujeitos se envolvem ativamente em interações (sempre mediadas por algum tipo de linguagem) para apresentar (re)elaborações de suas percepções do mundo. Desse modo, tem-se que a cognição só se constrói e se manifesta a partir do agir do indivíduo no mundo, da sua interação, seja com o meio social que o cerca, seja com outros indivíduos. Assim, o agir do sujeito contribui para o pensar desse sujeito.

Uma explicação sobre a interdependência entre sujeitos e o meio social em que vivem pode ser extraída a partir do que sugere Maturana ${ }^{3}$ (e colaboradores). Segundo o autor (1998, p. 67), “cada ser vivo é, em cada instante, o resultado do caminho de mudança estrutural que o mesmo [sic] seguiu a partir de sua estrutura inicial, como consequência de suas interações no meio no qual teve que viver" (grifo nosso). Dessa definição, importa destacar que as mudanças, decorrentes das interações nos mais diversos níveis, seriam sempre dependentes da estrutura inicial. Por isso é que "os seres vivos são sistemas nos quais as interações com o meio não determinam o que lhes acontece; somente disparam neles mudanças estruturais determinadas pela sua própria estrutura" (MATURANA e GARCÍA, 1998, p. 51).

Isso quer dizer que, nas interações, especialmente quando há recorrência, o papel dos agentes externos (do meio) seria o de permitir adequações estruturais já pertencentes aos seres vivos. Se fosse o contrário, ou seja, se os seres vivos fossem totalmente dependentes da interferência do meio, se não tivessem mecanismos próprios para responder "inteligentemente" às perturbações da interação, as chances de sobrevivência seriam escassas. Essa linha de raciocínio defende que não há, portanto, determinismo, mas, no dizer de Maturana e Varela (1998), acoplamento estrutural: modificação da organização (virtualmente prevista) em decorrência da interação.

\footnotetext{
${ }^{3}$ É importante salientar que a obra de Maturana, biólogo de formação, aborda, muitas vezes, os seres vivos, e não exclusivamente os seres humanos. Entre outros objetivos, o estudioso pretende mostrar que as bases sociocognitivas do agir humano encontra respaldo numa explicação biológica mais ampla.
} 
No que diz respeito à cognição humana, podemos dizer que seu funcionamento seria resultante dos diversos movimentos de acoplamento estrutural: a interação com o meio (incluindo-se aí os outros seres humanos) dispara mudanças no organismo, entendidas, no plano cognitivo, como a aquisição e mobilização de conhecimentos. $\mathrm{O}$ meio, conforme Maturana, apenas dispara e, de certa forma, orienta tais mudanças; o resto do trabalho - decisões sobre o papel da mudança na manutenção da organização estrutural - seria da alçada dos sujeitos.

Evidenciamos, então, primeiramente, a capacidade dos sujeitos de responder, de forma ativa, às demandas do meio social em que se encontram. Mas vimos, de acordo com Maturana e colaboradores, que o meio apenas dispara respostas que já estariam previstas na própria composição de um dado ser vivo. Disso, seria possível pensar que existe um outro tipo de determinismo: em virtude de uma "programação" biológica inerente a cada espécie, os seres vivos apresentariam respostas iguais para estímulos iguais - não haveria um determinismo social, mas sim um determinismo biológico. Trazendo a questão específica para a cognição humana, poderíamos dizer que as formas de refletir/agir são muito semelhantes, em virtude de a composição estrutural de um ser vivo determinar o modo como esse ser vivo atua perante o mundo.

Sobre isso, Maturana e Varela demonstram que a percepção dos seres é resultado das muitas e diferentes interações de que os organismos constantemente participam. E cada nova modificação, resultante do interagir, se dá com base em como o organismo se encontra naquele momento. Ou seja, cada nova perturbação (aquilo que, oriundo do meio social, faz que os organismos precisem dar algum tipo de resposta) é percebida levando em conta toda a bagagem acumulada até então. Como o conjunto de experiências de cada ser vivo é único, isso lhes garante a possibilidade de fornecer múltiplas respostas a um mesmo estímulo. E garante também, no que diz respeito à cognição humana, a multiplicidade de reflexões/ações que diferentes indivíduos podem ter, as quais dependem, em última instância, do seu percurso como ser que participa/age do/sobre o mundo.

A explicação proposta por Maturana e colaboradores vai ao encontro da necessidade de priorizar a interação como construto dinâmico e complexo, tão fundamental na vida dos seres vivos que somente a partir dela são construídas as relações que levam à aquisição e à reformulação dos conhecimentos. Atestar a relevância da interação, no que diz respeito à cognição humana, significa valorizar o papel da cultura, do entorno histórico e do contexto circunstancial na construção do 
conhecimento. No dizer de Koch e Cunha-Lima (2005, p. 279), temos que "as mentes individuais não aprendem uma computação abstrata, mas estão aprendendo a compreender um processo historicamente situado. Processos que são, ao mesmo tempo, compreendidos e transformados pelos indivíduos ao longo das suas histórias de vida".

A compreensão e a transformação dos processos, pelos indivíduos, permite concluir que, se a interação pressupõe ação dos sujeitos (e não apenas submissão), então, a percepção dos objetos e dos eventos do mundo se efetiva mediante reelaborações, dependentes dos interactantes e do contexto em que se encontram. Então, falar em sociocognição demanda uma reflexão importante sobre a relação entre o conhecimento, a linguagem e a "realidade".

Podemos dizer que a temática do real, no que toca à cognição, passa por duas bifurcações. A primeira delas diz respeito a decidir se as "coisas" do mundo têm ou não um papel preponderante no processo cognitivo. O caminho escolhido pelo sociocognição foi o da necessária inclusão do real no seu aparato teórico, a partir de onde surge o interesse pela cognição em interação. Escolhido o primeiro caminho, surge a segunda bifurcação, cujas estradas apontam ou para a estabilidade do mundo ou para a instabilidade do mundo ${ }^{4}$.

O sociocognitivismo investe na segunda trilha, assumindo a natureza constitutivamente instável do chamado "mundo real". Obviamente que a linguagem é o aspecto cognitivo mais produtivo para se tratar a questão, e é sobre essa relação que tratamos na próxima seção.

\section{Relações entre linguagem e sociocognição}

A rigor, há duas questões a tratar no que tange às relações entre linguagem e (socio)cognição: 1) qual a importância da linguagem para os estudos da cognição; 2) qual a importância da cognição para os estudos da linguagem.

O primeiro tópico pode ser tratado a partir da consideração de que a linguagem é um dos aspectos cognitivos mais “evidentes”, mais fáceis de se perceber"; por conta

\footnotetext{
${ }^{4}$ Para além da alçada exclusivamente cognitiva, os estudos linguísticos, quando alimentados por uma perspectiva filosófica, também se veem diante das mesmas bifurcações. Martins (2005, p. 440), por exemplo, aponta o mentalismo, o realismo e o pragmatismo como "três dos mais influentes paradigmas hoje disponíveis para o entendimento da linguagem". De fato, a construção das grandes correntes teóricas em linguística se movimenta em torno da exclusão da referência (mentalismo), da inclusão da referência como elemento depreendido do mundo (realismo) e da compreensão da referência como elaboração do mundo percebido (pragmatismo).

${ }^{5}$ Por isso Frawley (2000, p. 73-89) exemplifica os elementos básicos da ciência cognitiva (tradicional) com estudos sobre a linguagem, como os que discutem a organização sintática do inglês.
} 
disso, os fenômenos que envolvem a linguagem se revestem de momentos particularmente interessantes para que se explicitem algumas teses sobre, por exemplo, conhecimento e memória.

O aparato linguístico é relevante tanto para o cognitivismo clássico quanto para o sociocognitivismo ${ }^{6}$. No primeiro, temos que a crença de que é possível simular o pensamento humano em máquinas parte de uma concepção de linguagem e pode se manifestar, experimentalmente, a partir de formulações linguísticas. No segundo, vemos que a decisão metodológica de se considerarem as relações entre aspectos sociais e cognitivos para explicar o conhecimento só pode ser compreendida assumindo-se o papel fundamental da linguagem nos processos.

Temos, então, que o aspecto linguístico (inclusive a consideração do texto como unidade de linguagem ${ }^{7}$ ) é fundamental para que a teoria cognitiva estabeleça seus princípios. Caminhando na outra via da mesma estrada, vamos ver que o estudo do aspecto cognitivo é necessário para o desenvolvimento dos estudos da linguagem (ressaltando-se, contudo, que isso é válido mais para umas perspectivas do que para outras $\left.^{8}\right)$.

Quando se trata de discutir como a proposta sociocognitivista entra na agenda dos estudos linguísticos, é impossível não mencionar o papel fundamental da linguística textual (LT) em tal processo. É o texto como objeto de análise que permite a construção de um quadro investigativo privilegiado para que se percebam as profundas e constitutivas relações entre linguagem, conhecimento e cultura.

De fato, o desenvolvimento inicial da LT tem como motor gerador o cognitivismo (clássico). Conforme nos ensinam os textos introdutórios sobre o percurso histórico da disciplina (KOCH, 2004; BENTES, 2001), o breve período inicial das análises transfrásticas desembocou na necessidade de considerar que os fenômenos de

\footnotetext{
${ }^{6}$ Sobre as diferenças entre o cognitivismo clássico e o sociocognitivismo, sugerimos a leitura de Koch e Cunha-Lima (2005), Françoso e Albano (2005) e Custódio Filho (2011).

${ }^{7}$ Segundo Koch \& Cunha-Lima (2005), a teoria cognitiva tradicional procurou explicar o processamento textual atinente a tarefas como "identificar o tópico central de um texto, identificar seus temas principais, resumi-lo, fazer as inferências que geram a coesão e a coerência globais" (p. 290). As autoras informam, ainda, que "As tentativas de desenvolver métodos automáticos para o processamento de textos foi uma das fontes mais importantes para mostrar a inadequação da perspectiva cognitiva clássica” (p. 290-291).

${ }^{8}$ Um exemplo seria o Estruturalismo saussuriano, cujo aparato explicativo prescinde de qualquer menção à "mente do falante". A mesma decisão metodológica é percebida em perspectivas mais atuais, como a AD francesa e a Teoria da Argumentação na Língua. Embora se assuma (pelo menos no caso da AD francesa) que a linguagem só pode existir mediante um sistema cognitivo, não se considera essa ideia quando se trata de fazer as análises. Não lançamos mão dessa informação para criticar o fazer científico destas áreas. Apenas julgamos necessário destacar que, dentro dos estudos da linguagem, existem áreas cujos necessários recortes metodológicos descartam considerações mais pormenorizadas sobre a questão da cognição.
} 
concatenação eram regidos por regras que só seriam contempladas por análises em que se ultrapassassem os limites da sentença. Embalados pelo entusiasmo em torno das propostas de Chomsky, no seio da teoria gerativa, as quais inauguravam a necessidade de se tratar a linguagem como um fenômeno mental, os estudiosos passaram a tratar o texto como produto da cognição, regido por princípios mentais formalizáveis que dariam conta da capacidade humana de produzir e compreender enunciados adequados.

O período de tratamento excessivamente cognitivo do texto gerou lacunas que possibilitaram a emergência de um novo entendimento sobre o objeto, o que ativou a atenção dos pesquisadores não mais apenas para o produto, mas, principalmente, para os diversos aspectos envolvidos no processo de produção e compreensão. A tendência pragmática, que passa a tomar conta dos estudos, pode ser ilustrada com as palavras de Salomão (1999, p. 65):

\begin{abstract}
A rigor, para que existiria a linguagem? Certamente não para gerar sequências arbitrárias de símbolos nem para disponibilizar repertórios de unidades sistemáticas. Na verdade, a linguagem existe para que as pessoas possam relatar a estória de suas vidas, eventualmente mentir sobre elas, expressar seus desejos e temores, tentar resolver problemas, avaliar situações, influenciar seus interlocutores, predizer o futuro, planejar ações.
\end{abstract}

Essa perspectiva de investigação, por trazer o sujeito e seu contexto para o centro do processo, demanda uma nova abordagem da dimensão cognitiva. O processo de aquisição e ativação do conhecimento, agora regido sob o aparato sociocultural, é questão essencial para a compreensão do objeto texto. Segundo Koch \& Cunha-Lima (2005, p. 292), uma das principais teses da LT, formulada nesse estágio, foi a de que

nenhum texto é ou poderia ser completamente explícito, já que [...] os processos de produção e de compreensão de textos dependem, em grande parte, de informações que são apenas sugeridas, apontadas nos/pelos textos e que devem ser mobilizadas pelo ouvinte/leitor para que consiga estabelecer adequadamente o(s) sentido(s) global(is) de um texto.

É nesse momento que texto e sociocognição passam a se encontrar. A natureza inerentemente "incompleta" dos textos implica a necessidade de buscar a completude fora da materialidade linguística, o que demanda a mobilização de conhecimentos. Acontece que, no panorama que passou a se esboçar, o conhecimento não é mais tratado como o resultado de operações de representação mental baseadas no raciocínio lógico- 
matemático ${ }^{9}$; o conhecimento é o resultado de operações dos sujeitos em interação, e por isso mesmo é seletivo e passível de mudança, a depender de cada situação.

Temos, então, que os vários fenômenos envolvidos na estruturação textual apresentam uma natureza multifacetada, em virtude de estarem sujeitos à pressão de diversas forças (conhecimentos), armazenadas, de forma dinâmica, no cérebro. $O$ texto é, pois, a unidade fundamental da interação; por isso, "é natural que os estudos de texto tenham um papel central na encruzilhada onde se encontram preocupações com a cognição e com a vida social" (KOCH e CUNHA-LIMA, 2005, p. 294).

Podemos considerar que o assumir o sociocognitivismo como proposta teórica basilar é quase uma reivindicação natural dos estudos em LT. A disciplina só tem a fisionomia atual porque se sustenta sobre essa base. Os princípios da primazia da interação e da noção de realidade como construto prenhe de significação, apresentados na primeira seção, são os mesmos que embasam o fazer atual da LT. Temos, assim, que a sociocognição e a LT se amparam mutuamente; uma é absolutamente necessária para o sustento da outra.

É preciso salientar, contudo, que, do lado da LT, observa-se uma ênfase na consideração do aspecto discursivo-ideológico envolvido no aparato social da linguagem. Grosso modo, podemos dizer que a consideração da interação como elemento central decorre principalmente de uma postura pragmática. $\mathrm{O}$ argumento de que cada interação é um momento único - que, sem sombra de dúvidas, ganha mais força quando relacionado ao conceito de acoplamento estrutural de Maturana e colaboradores ${ }^{10}$ - prioriza a natureza circunstancial do fenômeno cognitivo, o que fala em favor de considerar os aspectos situacionais como intervenientes importantes do processo de conhecer. Trazendo a questão para a seara da linguagem, poderíamos dizer, verdadeiramente, que a produção e a compreensão de textos dependem dos papéis assumidos pelos sujeitos, sendo que tais papéis são flutuantes, dependentes de cada interação.

Para além da questão circunstancial, é preciso considerar que o caráter social da linguagem contempla os aspectos ideológicos atinentes à comunicação. Os papéis assumidos pelos participantes de uma interação não são determinados exclusivamente pelas características da situação, mas pela constituição dos sujeitos atravessados pela

\footnotetext{
${ }^{9}$ Defendemos que há, sim, representações, mas essas não necessariamente se conformam ao aparato racional. Sobre isso, consultar os trabalhos sobre referenciação (dentre outros, CAVALCANTE, 2011; CUSTÓDIO FILHO, 2011; CAVALCANTE, CUSTÓDIO FILHO e BRITO, 2014).

${ }^{10}$ Maturana (1998); Maturana e García (1998); Maturana e Varela (1998).
} 
ideologia $^{11}$. Daí a LT assumir, hoje, como elementos fundamentais para uma teoria do texto, conceitos como os de heterogeneidade e de polifonia.

Particularmente para a LT, a sociocognição é vinculada ao discurso. O conhecimento, no que diz respeito à produção e ao processamento, está vinculado a mecanismos institucionais de controle que, além de regularem as situações comunicativas em termos do que pode ser dito por quem, afetam diretamente a bagagem cognitiva dos sujeitos. Por isso é que, na atualidade, a inclusão dos aspectos sociais nos estudos em cognição não se limita ao tratamento pragmático dos fenômenos; mais adequado é falar num tratamento pragmático-discursivo, mesmo que, para alguns, esse não seja um caminho produtivo ou possível ${ }^{12}$.

Com essa perspectiva, a LT contribui para a solidificação de uma proposta, de alcance multidisciplinar, que advoga em favor da intrínseca relação entre pensamento, linguagem, cultura, situação de comunicação e discurso. A relação entre esses elementos é, de fato, inextricável a tal ponto que, como nos diz Salomão (1999, p. 71), há

uma continuidade essencial entre linguagem, conhecimento e realidade que não as reduz entre si, mas as redefine em sua fragmentária identidade (como realidade, ou como conhecimento, ou como linguagem), segundo as necessidades locais da interação humana.

Assim, a "realidade" pode ser focalizada como "conhecimento" (obviamente, não há conhecimento que recubra, ou substitua, a realidade). Do mesmo modo, o "conhecimento" pode assomar como "linguagem".

O que Salomão indica é que, embora essas três instâncias não sejam exatamente equivalentes, uma é absolutamente essencial para que a outra se manifeste, de modo que saber exatamente onde termina a realidade e começa o conhecimento, e onde este termina e começa a linguagem, é tarefa impossível.

Um esquema que nos permite visualizar a interpenetração entre as diversas instâncias que determinam a configuração dos sentidos é o proposto por Blikstein (2003). Procurando continuar a extensa investigação linguístico-semiológica acerca da

\footnotetext{
${ }^{11}$ Discutindo sobre as concepções de sujeito, Koch (2003) afirma que a concepção majoritariamente aceita em LT, na atualidade, advoga em favor de um sujeito que é, ao mesmo tempo, reprodutor (porque se encontra atravessado pela ideologia) e produtor (porque participa ativamente na definição da situação na qual se acha engajado) da conjuntura social. Dentro dessa visão, segundo a autora, "Chega-se [...] a um equilíbrio entre sujeito e sistema, entre a 'socialização' e a produção do social" (p. 16).

${ }^{12}$ Ver, sobre isso, a posição de Possenti (2005, p. 363), para quem “A Pragmática [...] disputa com a AD [Análise do Discurso] o mesmo espaço - o do sentido "não-literal" (grifo nosso).
} 
natureza e do lugar do acontecimento semântico ("Como e quando eclode a significação? Em que momento da cognição irrompe o significado?” - 2003, p. 23), o autor delega à questão do referente um papel fundamental numa teorização que avance em relação à incompleta abordagem que extradita a realidade extralinguística (o referente) de suas formulações.

A captura do referente, segundo Blikstein, é necessária para que as ciências preocupadas com a busca pelo sentido expliquem coerentemente os fenômenos que pretendem abordar. Essa captura passa, obrigatoriamente, pela consideração de fatores que vão além do sistema linguístico. Entra em cena a cognição:

O fato de o referente ser extralinguístico não significa que deva ficar fora da linguística; ele simplesmente está situado atrás ou antes da linguagem, como um evento cognitivo, produto de nossa percepção. Qualquer que seja o nome de tal "produto", seja referente, objeto mental ou unidade cultural, fica reconhecida a necessidade do recurso a uma dimensão anterior à própria experiência verbal para a detecção da gênese do significado. Tal dimensão [...] é a percepção-cognição" (BLIKSTEIN, 2003, p. 39, grifos do autor).

Considerando, então, a dimensão cognitiva como participante do acontecimento semântico, Blikstein dedica-se a explicar qual seria o papel dela na produção dos sentidos. Inicialmente, ele critica as famosas abordagens que encaram as relações instauradas na linguagem como triádicas, que definem as categorias de significante, significado e referente, quase sempre com a preocupação de extraditar o referente das considerações mais pertinentes. A primeira grande contribuição do autor é mostrar que o referente não é igual à coisa extralinguística, à coisa do mundo; o referente é, antes, uma fabricação, que se relaciona com a realidade por intermédio da percepção, conforme o esquema a seguir.

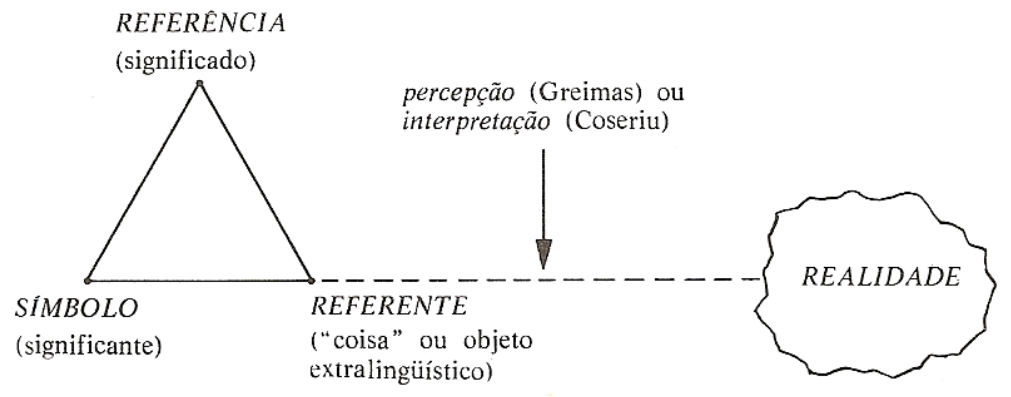


Gráfico 1 - Relação entre percepção e referente ${ }^{13}$ (BLIKSTEIN, 2003, p. 46).

Blikstein vai complexificando o seu esquema inicial de modo a mostrar como a dimensão perceptual coordena a relação entre realidade e referente, enfatizando a influência dos aspectos sociais na percepção, bem como a natureza cíclica dos elementos envolvidos no processo. O resultado final de suas reflexões desemboca no esquema a seguir:

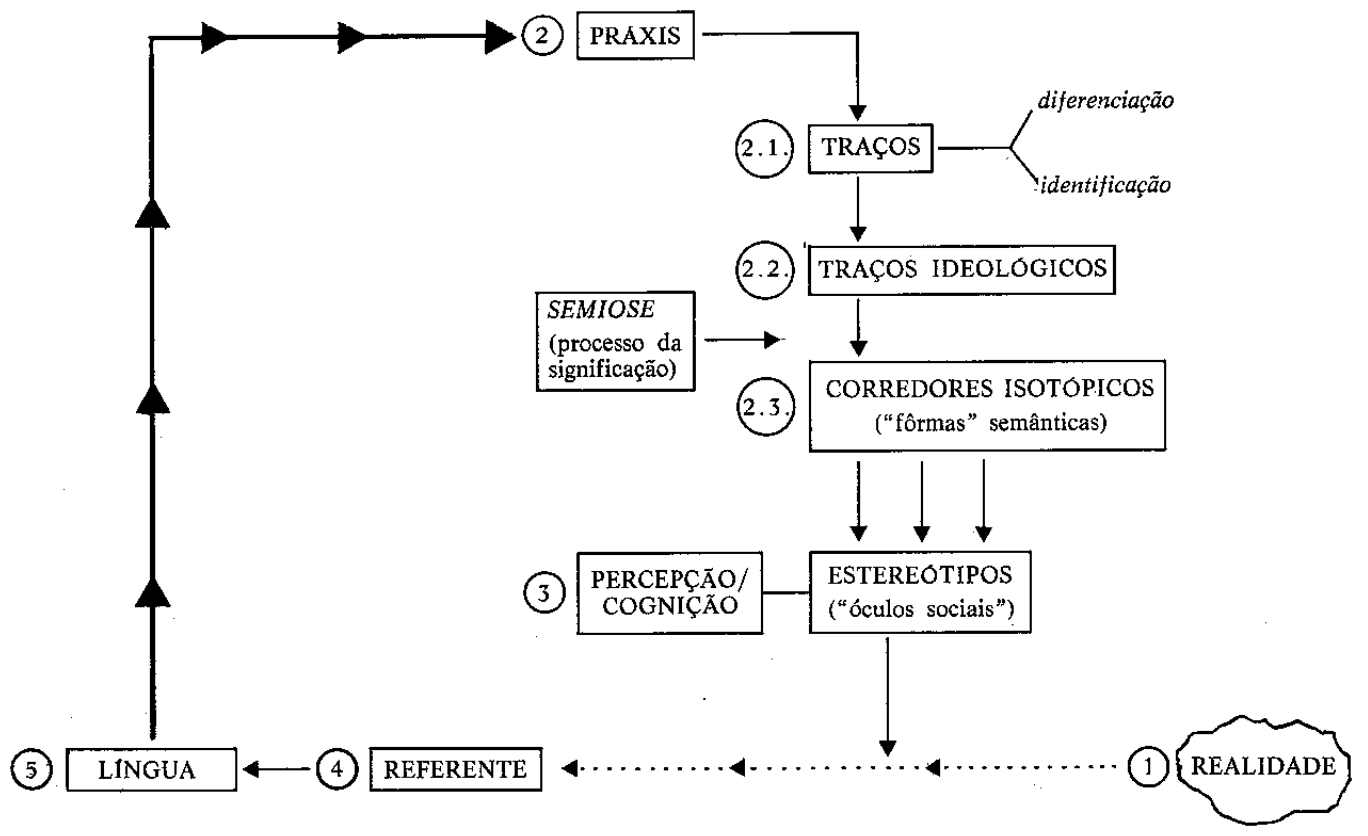

Gráfico 2 - A interação realidade / referente / língua / práxis (BLIKSTEIN, 2003, p. 81).

Pelo esquema proposto, percebe-se que a práxis ${ }^{14}$ "modela" a percepção/cognição e gera a significação da realidade. No processo, são relevantes as operações de identificação e diferenciação, que respondem à necessidade humana de discriminação, separação e agrupamento, de onde surge o reconhecimento de categorias e eventos, necessário à sobrevivência. Os traços resultantes das operações de identificação e diferenciação ganham valores, positivos ou negativos, impingidos socialmente, que garantem, em última instância, o seu caráter ideológico. Os traços ideológicos condicionam as linhas básicas da significação, pois eles determinam corredores semânticos, enquadres conceituais responsáveis pela construção dos

\footnotetext{
${ }^{13}$ Os nomes de Greimas e Coseriu aparecem no gráfico porque, em sua exposição do estado da arte no que toca aos estudos sobre o referente, Blikstein procura mostrar que termos diferentes usados por diferentes teóricos teriam alguma equivalência.

${ }^{14}$ Blikstein (2003, p. 54) utiliza o conceito marxista de práxis: "conjunto de atividades humanas que engendram não só as condições de produção, mas, de um modo geral, as condições de existência de uma sociedade".
} 
estereótipos, ou “óculos sociais". Com estes óculos é que percebemos o mundo ${ }^{15}$; é através dessas lentes que fabricamos a realidade e construímos os referentes.

O esquema destaca, ainda, o papel da linguagem no processo da significação. Embora enfatize reiteradamente a necessidade de se valorizar a existência de uma dimensão de significação não verbal, Blikstein reconhece que a linguagem atua também no processo de significação, na medida em que materializa os estereótipos e reitera a práxis. Segundo o autor (2003, p. 79-80),

a impossibilidade de capturar a semiose não verbal, que se desencadeia na dimensão oculta entre a práxis e o referente, compele o indivíduo a recorrer ao sistema verbal para materializar e compreender a significação escondida. [...] estabelece-se uma interação entre língua e práxis, a tal ponto que, quanto mais avançamos no processo de socialização, mas difícil se torna separar as fronteiras entre ambas. Agindo sobre a práxis, a língua também pode modelar o referente e "fabricar" a realidade.

Blikstein corrobora a pertinência de seu esquema com a história de Kaspar Hause. Até os 18 anos, quando chega numa cidade alemã, o jovem não havia tido nenhum contato humano de que se lembrasse. Ele é acolhido por um morador da cidade e começa a participar da comunidade. Mesmo passando a ser instruído no código linguístico, Kaspar Hause não consegue se adaptar à nova vida, em virtude de não conseguir esboçar um comportamento social adequado. Não poderia ser diferente, já que o rapaz não tinha como fabricar os referentes necessários a sua conduta, pois lhe faltavam os óculos sociais.

O exemplo de Kaspar Hause mostra que, de um lado, é necessário considerar outros aspectos, além do linguístico, quando se trata de investigar o acontecimento semântico; de outro lado, percebe-se a importância fundamental da linguagem na regulação e controle das significações percebidas.

Com esse e outros exemplos, Blikstein confirma a pertinência de uma perspectiva que enxergue a relação cíclica entre linguagem, atividade humana e cognição, e é exatamente por isso que o trabalho do autor figura nesta discussão sobre o sociocognitivismo. Embora não seja um teórico considerado como filiado ao sociocognitivismo ou à linguística textual, a consonância de suas ideias com as

\footnotetext{
${ }^{15}$ Como dizem Kress \& van Leeuwen (2006, p. 158), "a realidade pode estar no olho do observador, mas o olho tem um treino cultural, e é localizado numa moldura social e numa história" - tradução nossa para "reality may be in the eye of the beholder, but the eye has had a cultural training, and is located in a social setting and a history".
} 
defendidas nessas duas áreas ${ }^{16}$ é motivo mais que suficiente para lhe garantir lugar de destaque nas reflexões.

Além disso, a proposta de Blikstein deixa patente a relevância do referente para a construção de teorias linguísticas (e também sociocognitivistas). De modo geral, percebemos que toda proposta de teorização da linguagem demanda uma decisão sobre qual o papel da referência no seu quadro teórico. Ao contrário das teorias que decidem pela exclusão ou minimização do papel do referente, o pesquisador coloca a questão como central, alocando o referente como a unidade que permite as inter-relações entre língua, práxis e cognição, o que o aproxima da proposta da referenciação.

Sobre a referenciação, Mondada e Dubois (2003) afirmam que a maior parte dos teóricos (especialmente, mas não só, os ligados à linguística) opta por salientar uma relação de equivalência entre as palavras e as coisas, de onde vem a concepção de língua como representação adequada da realidade. Elas lembram, ainda, que o senso comum partilha de tal visão, pois a crença em um mundo exterior estabilizado permite um acesso mais fácil à compreensão da realidade cotidiana. As autoras abordarão a questão da relação entre língua e realidade num panorama bem diferente do exposto, enfatizando, entre outras coisas, a natureza sociocognitiva do fenômeno.

Falar que a referenciação resulta de um trabalho sociocognitivo implica dizer que a construção dos objetos do texto, necessária à produção de sentidos, passa por alguma forma de processamento mental, considerando-se que tal trabalho se efetiva a partir de parâmetros sociodiscursivos previamente apreendidos e atualizáveis em cada situação de interação. Isso pode ser percebido a partir da análise da piada apresentada a seguir $^{17}$.

E tem aquela do sujeito que chega em casa e encontra a filha agarradinha com o namorado. Aliás, bem agarradinha. O pai então dá o maior estrilo:

- Que pouca vergonha é essa?!

E o rapaz, todo sem jeito:

- Bem, o senhor sabe, eu estou apenas mostrando a minha afeição para a sua filha.

E o pai da moça:

- É! Tô vendo que sua afeição é grande! Mas bota ela pra dentro da calça!... (SARRUMOR. Ainda mais mil piadas do Brasil. Retirado de LIMA, 2007.)

Nessa piada, a expressão referencial "afeição", ao ser utilizada pelo pai da moça, está categorizando o referente "órgão sexual masculino". Não há, no texto, uma

\footnotetext{
${ }^{16}$ Veja-se, por exemplo, como a questão do discurso, presente na obra de Blikstein a partir das considerações sobre o caráter ideológico dos estereótipos, já antecipa as reflexões atuais da linguística textual.

${ }^{17}$ As considerações aqui apresentadas baseiam-se em análises feitas inicialmente por Lima (2007) e Leite (2007).
} 
confirmação explícita dessa relação entre a expressão e o referente, no entanto é possível percebê-la muito claramente. Somos capazes de fazer essa associação porque trabalhamos cognitivamente a partir das pistas co(n)textuais, ou seja, usamos nossa capacidade intelectiva para estabelecer as relações textuais explícitas e implícitas. No caso do texto, algumas pistas nos ajudam a fazer essas conexões: o fato de a afeição do rapaz, segundo o pai da moça, ser grande e de ela estar fora da calça.

$\mathrm{Na}$ piada que acabamos de ler, percebemos como o conhecimento social é relevante para a interpretação do referente: para o entendimento da relação entre a expressão "afeição" e o referente "órgão sexual masculino", é necessário conhecer (ou porque se viveu ou porque se ouviu sobre) a experiência de namoro "bem agarradinho", no qual a excitação sexual é bastante acentuada. De posse desse conhecimento social, podemos perceber como o termo "afeição" passa a ter duplo sentido, gerando o humor do texto.

Vemos, então, que o processo referencial é essencialmente sociocognitivo. De um lado, o aspecto social põe em relevo a necessidade de se analisarem os referentes linguísticos sob o foco dos vários fatores sociais que interferem na configuração textual e que se localizam além dos fatores estritamente linguísticos. De outro lado, o aspecto cognitivo enfatiza que o processamento referencial é cognitivamente motivado, estratégico, no sentido de que os interlocutores selecionam formas de atuar sobre a produção e recepção de textos, utilizando, para tanto, o conhecimento (em algum nível) proveniente de sua "bagagem" mental.

Temos, então, que a produção dos sentidos só se dá mediante uma ação sociocognitiva dos sujeitos. Como tentamos demonstrar nessa exposição, texto, conhecimento e interação são instâncias inerentemente interdependentes, e cabe aos linguistas de texto não apenas reconhecer essa relação, mas também propor análises coerentes com esse posicionamento. Para tanto, cremos que o conhecimento sobre os principais parâmetros da teoria sociocognitiva pode ser útil no que concerne à delineação de procedimentos metodológicos de análise e discussão.

\section{Conclusão}

Procuramos, com este artigo, explicitar as principais características do sociocognitivismo no que toca às suas relações com a linguagem. Defendemos que os conceitos apresentados são fundamentais para a compreensão do conceito de texto 
assumido pela linguística textual na atualidade, e também para a compreensão do fenômeno da referenciação como estratégia textual-discursivo-cognitiva. Com isso, consideramos que o viés sociocognitivista exige dos pesquisadores algumas posturas investigativas que, se levadas a cabo, possibilitam a emergência de novos achados sobre os fenômenos textuais. Os avanços permitidos pelos novos achados guardam estreita relação com o paradigma adotado; nele, já estão incluídos os princípios que, se efetivamente levados a cabo, promovem o aprimoramento das explicações teóricas.

Nesse processo, merece destaque o agir dos sujeitos: ao participarem ativamente da interação, eles também geram conhecimentos. A construção dos sentidos só é possível, portanto, porque os interlocutores associam o aparato material do texto aos seus conhecimentos (devendo este termo ser entendido numa acepção bem ampla). Explicitar a relação sociocognição e linguística textual é, em última instância, acreditar numa linguística que leva em conta o que mais importa: desvendar o que é o humano como ele se constrói e como, nessa construção, reforça ou transforma o meio que o abriga.

\section{REFERÊNCIAS}

BENTES, A. C. linguística textual. In: MUSSAliM, F.; BENTES, A. C. (Org.). Introdução à linguística: domínios e fronteiras, v. 1. 2. ed. São Paulo: Cortez, 2001, p. 245-287.

BLIKSTEIN, I. Kaspar Hause, ou a fabricação da realidade. 9. ed. São Paulo: Cultrix, 2003.

CAVALCANTE, M. M. Referenciação: sobre coisas ditas e não ditas. Fortaleza: Edições UFC, 2011.

CAVAlCANTE, M. M.; CUSTÓDIO FILHO, V.; BRITO, M. A. P. Coerência, referenciação e ensino. São Paulo: Cortez, 2014.

CUSTÓDIO FILHO, V. Múltiplos fatores, distintas interações: esmiuçando o caráter heterogêneo da referenciação. 329p. Tese (Doutorado em Linguística). Universidade Federal do Ceará, Fortaleza, 2011.

FRANÇOSO, E.; ALBANO, E. Virtudes e vicissitudes do cognitivismo, revisitadas. In: MUSSALIM, F.; BENTES, A. C. (Org.). Introdução à linguística. v. 3: fundamentos epistemológicos. 2. ed. São Paulo: Cortez, 2005, p. 301-310.

FRAWLEY, W. Vygotsky e a ciência cognitiva: linguagem e integração das mentes social e computacional. Tradução Marcos A. G. Domingues. Porto Alegre: Artes Médicas Sul, 2000.

KOCH, I. G. V. Desvendando os segredos do texto. 2. ed. São Paulo: Cortez, 2003. . Introdução à linguística textual: trajetória e grandes temas. São Paulo: Martins Fontes, 2004.

KOCH, I. G. V.; CUNHA-LIMA, M. L. Do cognitivismo ao sociocognitivismo. In: MUSSALIM, F.; BENTES, A. C. (Org.). Introdução à linguística. v. 3: fundamentos epistemológicos. 2. ed. São Paulo: Cortez, 2005, p. 251-300. 
KRESS, G.; van LEEUWEN, T. Reading images: the grammar of visual design. 2. ed. Londres, Nova York: Routledge, 2006.

LEITE, R. L. Metaforização textual: a construção discursiva do sentido metafórico no texto. 212p. Tese (Doutorado em Linguística). Universidade Federal do Ceará, Fortaleza, 2007.

LIMA, S. M. C. Recategorização metafórica e humor: uma proposta classificatória. In: CAVAlCANTE, M. M. et al (Org.) Texto e discurso sob múltiplos olhares. v. 2: referenciação e outros domínios discursivos. Rio de Janeiro: Lucerna, 2007, p. 74-103.

MARTINS, H. Três caminhos na filosofia da linguagem. In: MUSSALIM, F.; BENTES, A. C. (Org.). Introdução à linguística. v. 3: fundamentos epistemológicos. 2. ed. São Paulo: Cortez, 2005, p. 439-473.

MATURANA, H. R. Reflexões: aprendizagem ou derivação ontogênica? In: GARCÍA, J. L. (Org.). Da biologia à psicologia. Tradução Juan Acuña Llorens. 3. ed. Porto Alegre: Artes Médicas, 1998, p 31-47.

MATURANA, H. R.; GARCÍA, J. L. Herança e meio ambiente. In: GARCÍA, J. L. (Org.). Da biologia à psicologia. Tradução Juan Acuña Llorens. 3. ed. Porto Alegre: Artes Médicas, 1998, p 49-54.

MATURANA, H. R.; VARELA, F. J. The tree of knowledge - revised edition. Tradução Robert Paolucci. Boston, Londres: Shambhala, 1998.

MONDADA, L.; DUBOIS, D. Construção dos objetos de discurso e categorização: uma abordagem dos processos de referenciação. Tradução Mônica Magalhães Cavalcante. In: CAVAlCANTE, M. M.; BIASI-RODRIGUES, B.; CIULlA e SILVA, A. (Org.). Referenciação. São Paulo: Contexto, 2003, p. 17-52.

POSSENTI, S. Teoria do discurso: um caso de múltiplas rupturas. In: MUSSALIM, F.; BENTES, A. C. (Org.). Introdução à linguística. v. 3: fundamentos epistemológicos. 2. ed. São Paulo: Cortez, 2005, p. 353-392.

SALOMÃO, M. M. M. A questão da construção do sentido e a revisão da agenda dos estudos da linguagem. Veredas: Revista de Estudos Linguísticos. Juiz de Fora, v. 3, n. 1, p. 61-79, 1999.

Recebido em 31/03/2018. Aceito em 06/06/2018. 